\title{
Mitral valve replacement in patients with severe mitral calcification
}

\author{
Gabriele M. Iacona, MD, ${ }^{\mathrm{a}}$ Syed O. Ali, MD, ${ }^{\mathrm{a}}$ Shinya Unai, MD, ${ }^{\mathrm{a}}$ Serge C. Harb, MD, ${ }^{\mathrm{b}}$ and \\ Gosta B. Pettersson, MD, PhD, ${ }^{\text {a }}$ Cleveland, Ohio
}

\footnotetext{
From the ${ }^{\mathrm{a} D e p a r t m e n t}$ of Thoracic and Cardiovascular Surgery, Heart Vascular \& Thoracic Institute, and ${ }^{\mathrm{b}}$ Cardiovascular Imaging, Heart Vascular \& Thoracic Institute, Cleveland Clinic, Cleveland, Ohio.

This report was funded by the Peter and Elizabeth C. Tower and Family Endowed Chair in Cardiothoracic Research.

Disclosures: The authors reported no conflicts of interest.

The Journal policy requires editors and reviewers to disclose conflicts of interest and to decline handling or reviewing manuscripts for which they may have a conflict of interest. The editors and reviewers of this article have no conflicts of interest.

Received for publication May 26, 2021; accepted for publication Nov 1, 2021; available ahead of print Nov 9 , 2021.

Address for reprints: Shinya Unai, MD, Department of Thoracic and Cardiovascular Surgery, Heart Vascular \& Thoracic Institute, Cleveland Clinic, Desk J4-1, 9500 Euclid Ave, Cleveland, OH 44195 (E-mail: unais@ @cf. org).

JTCVS Techniques 2022;11:7-9

2666-2507

Copyright (C 2021 The Authors. Published by Elsevier Inc. on behalf of The American Association for Thoracic Surgery. This is an open access article under the CC BY-NC-ND license (http://creativecommons.org/licenses/bync-nd/4.0/)

https://doi.org/10.1016/j.xjtc.2021.11.001
}

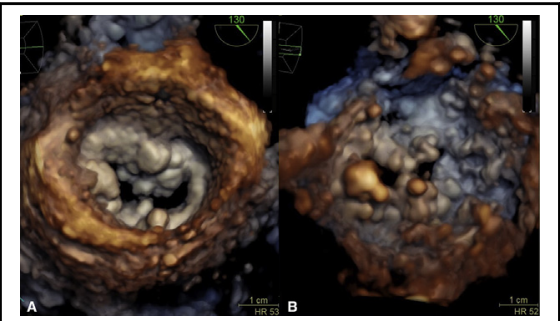

3D TEE: calcified mitral annulus and mitral leaflets. $A$, atrial view; $B$, ventricular view.

CENTRAL MESSAGE

Mitral valve replacement with severe mitral calcification requires debridement of calcium to place a prosthesis of acceptable size and rely on the strength of patch supported valve sutures

See Commentary on page 10.
Mitral annular calcification (MAC) is a chronic degenerative process in the fibrous base of the mitral valve, complicating mitral valve surgery and resulting in greater mortality. ${ }^{1}$ We present a case of mitral valve replacement (MVR) with severe MAC, tricuspid valve repair, and aortic valve replacement.

Institutional review board approval and patient's informed consent were not required for this report. Our patient was a 74-year-old female patient with severe mitral stenosis and severe MAC, moderate aortic valve stenosis, moderate tricuspid regurgitation, and previous history of coronary artery bypass graft (patent left internal mammary artery to left anterior descending, patent vein grafts to obtuse marginal and diagonal branches). After repeat median sternotomy, standard cardiopulmonary bypass was initiated and the heart arrested with antegrade and direct retrograde cardioplegia. The mammary graft was dissected and clamped. Aortotomy was performed and aortic valve was excised and annulus debrided. The mitral valve was approached through the right atrium and atrial septum. Valve leaflets were excised preserving anterior chordae (Video 1). ${ }^{2}$ To achieve a debridement of the MAC, we used a combined transseptal and transaortic approach. The MAC was debrided as much as needed to seat a valve of acceptable size, with care taken not to violate the posterior capsule of the calcium bar. The mitral annulus was thoroughly sized. A half oval bovine pericardial patch was first sewn at the transition between MAC and healthy myocardial muscle in the left ventricle using a running suture with 4-0 RB1 monofilament suture. Valve sutures with pledgets were placed circumferentially. Posteriorly, these sutures passed through the ventricular side of the patch, through the atrial lip of the calcium bar, and back through the patch on the atrial side. Then, we secured the patch to the atrial wall with a running suture. Aortic valve sutures were placed and aortic valve was sized. A mitral bioprosthesis was then implanted and sutures tied, following which an aortic bioprosthesis was placed. A tricuspid repair was performed with a ring annuloplasty. The patient was weaned of cardiopulmonary bypass with low dose inotropic support. Postoperatively, she developed junctional bradycardia requiring a permanent pacemaker, acute renal failure, left pleural effusion, and atrial fibrillation. She was discharged from hospital on postoperative day 21 , 


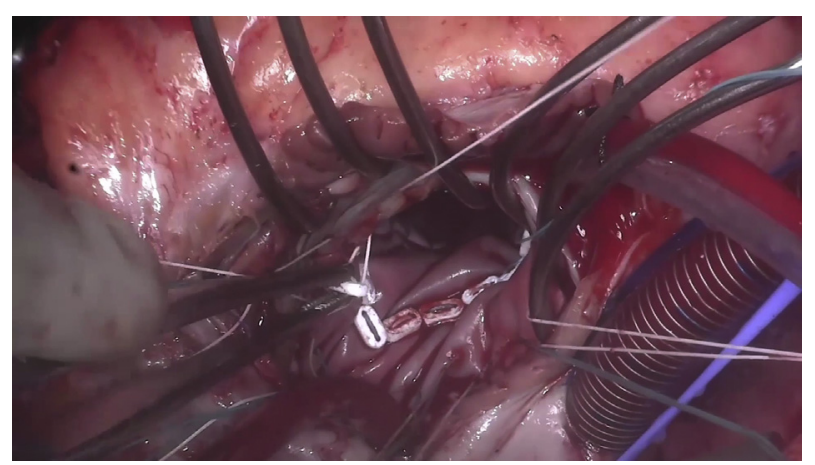

VIDEO 1. Mitral annular calcification (MAC) is a chronic degenerative process in the fibrous base of the mitral valve complicating mitral valve surgery. We present a case of mitral valve replacement (MVR) with severe MAC approached with the patch technique. The mitral valve is exposed through the right atrium and atrial septum. Valve leaflets are excised preserving some anterior chordae. Our debridement is guided by the ability to implant a prosthesis of appropriate size and place sutures through or around calcium when the calcium bar is not too wide. Debridement, however, often results in a wide grove with some remaining calcium in the bottom and intact capsule. To achieve a debridement of the MAC through a perfect exposure, we normally use a combined transseptal and transaortic approach. The exposed debrided mitral annulus has to be completely covered with the patch which adds support for the sutures and may reduce the risk of calcium embolization. ${ }^{2}$ Oversizing of the patch is a critical step. The patch is first sewn at the transition between MAC and healthy myocardial muscle in the left ventricle. Then posterior valve sutures are passed through the patch, through the capsule, and the atrial lip of the MAC. The placement of these sutures must leave no tension on the patch and the ventricular suture line. Valve stitches go back through the patch. The patch is trimmed and secured to the atrial wall. Anterior stiches with pledgets are placed. MVR is completed. The patch technique is a safe procedure for MVR with MAC. Transseptal and transaortic approach, limited debridement of calcium, and well-anchored and supported valve sutures are keys to success. It is a complex surgical technique for expert cardiac surgeons. Video available at: https://www.jtcvs.org/article/S2666-2507(21)00757-4/fulltext. with underlying controlled atrial fibrillation. Postoperative echocardiogram showed no paravalvular leak with a mean gradient of $3 \mathrm{mmHg}$.

Different approaches to MAC have been described from very limited MAC removal to extended decalcification. ${ }^{3-5}$ Too aggressive attempts to remove MAC may cause atrioventricular grove rupture. ${ }^{1}$ Most surgeons are wary of MAC, as it is associated with low likelihood of a successful mitral valve repair or MVR and often results in implantation of a small prosthesis with a high risk of paravalvular leaks. Our debridement is guided by the ability to implant a prosthesis of appropriate size and place sutures through or around calcium when the calcium bar is not too wide. After debridement (and before/after patch placement), the mitral valve should be carefully sized with valve sizers to be sure that a suitable prosthesis can be implanted. Debridement, however, often results in a wide groove, with some remaining calcium in the bottom and intact capsule. The valve sutures rely on the strength of this capsule. The placement of these sutures must leave no tension on the patch and the ventricular suture line. Oversizing of the patch is a critical step. When a patch is used, the exposed debrided mitral annulus is completely covered with the patch which adds further support for the sutures and may reduce the risk of calcium embolization. ${ }^{2}$

This technique has several limitations, as it adds further to the duration of the procedure. The patch is sutured directly to the myocardium on the ventricular side. Often, the residual calcium and its ventricular extension makes placing a patch difficult and time-consuming, and just using a continuous felt strip in the bottom of the calcium grove is an acceptable alternative. In older patients, this myocardial muscle can be fragile and prone to bleeding and patch

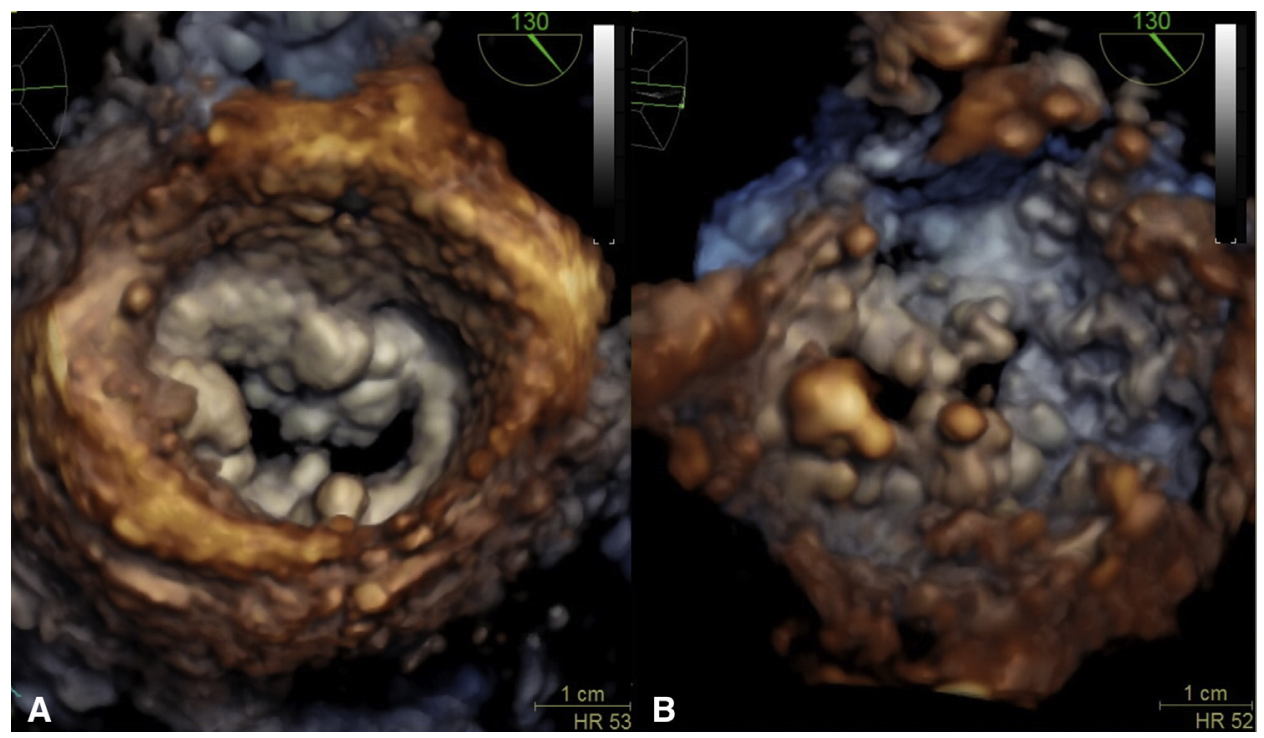

FIGURE 1. Transesophageal echocardiography showing narrow calcified mitral annulus with retracted and calcified mitral leaflets. A, Atrial view; B, ventricular view. 


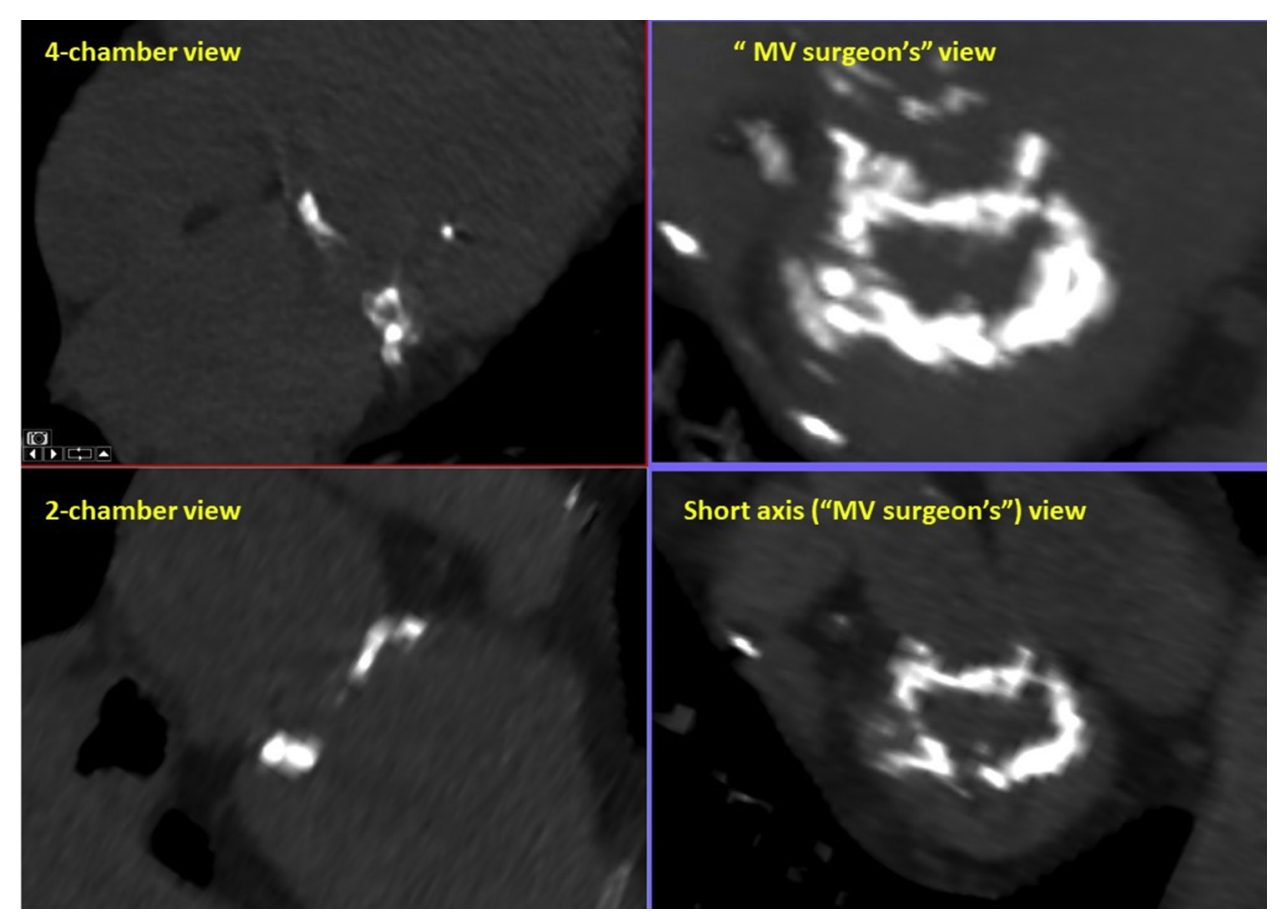

FIGURE 2. Cardiac computed tomography. $M V$, Mitral valve.

dehiscence soon after removal of the aortic crossclamp. Debridement of the MAC is always a long procedure that requires perfect myocardial protection with antegrade and direct retrograde cardioplegia delivery. It is critically important to review preoperatively the echocardiogram (Figure 1) and the cardiac computed tomography (Figure 2) looking at the extent of calcium and location of the circumflex artery.

A dual, transseptal and transaortic approach, limited debridement of calcium, and well-anchored and supported valve sutures are keys to successful and safe MVR in patients with severe MAC.

\section{References}

1. Abramowitz Y, Jilaihawi H, Chakravarty T, Mack MJ, Makkar RR. Mitral annulus calcification. J Am Coll Cardiol. 2015;66:1934-41.

2. Ben-Avi R, Orlov B, Sternik L, Kogan A, Kuperstien R, Shalabi A, et al. Short- and long-term results after prosthetic mitral valve implantation in patients with severe mitral annulus calcification $\dagger$. Interact Cardiovasc Thorac Surg. 2017;24:876-81.

3. Carpentier AF, Pellerin M, Fuzellier JF, Relland JY. Extensive calcification of the mitral valve anulus: pathology and surgical management. J Thorac Cardiovasc Surg. 1996;111:718-29; discussion 729-30.

4. Mihaljevic T, Koprivanac M, Kelava M, Smedira NG, Lytle BW, Blackstone EH Mitral valve replacement in patients with severely calcified mitral valve annulus: surgical technique. J Thorac Cardiovasc Surg. 2013;146:233-5.

5. Pizano A, Hirji SA, Nguyen TC. Severe mitral annular calcification and mitral valve surgery: an algorithmic approach to management. Semin Thorac Cardiovasc Surg. 2020;32:630-4. 